\title{
Progressive Primary Plate-Like Osteoma Cutis of the Scalp
}

\author{
Farnaz Araghi $^{a}$ Sahar Dadkhahfar ${ }^{a}$ Mohammadreza Tabary ${ }^{b}$ \\ Azadeh Rakhshanc Mehdi Gheisaria, d
}

${ }^{a}$ Skin Research Center, Shahid Beheshti University of Medical Sciences, Tehran, Iran; ${ }^{\text {b}}$ Experimental Medicine Research Center, Tehran University of Medical Sciences, Tehran, Iran; 'Department of Pathology, Shohada-e-Tajrish Educational Hospital, School of Medicine, Shahid Beheshti University of Medical Sciences, Tehran, Iran; dDepartment of Dermatology, Loghman Hakim Hospital, Shahid Beheshti University of Medical Sciences, Tehran, Iran

\section{Established Facts}

- Osteoma cutis (OC) is characterized by an ectopic bone formation in the skin.

- OC is categorized into primary and secondary types.

- Primary OC lesions have been reported on the face, scalp, trunk, breast, extremities, and buttocks.

- OC in plaque defines a congenital, idiopathic, and plaque-like primary OC which has been reported occasionally in older children or even adults.

\section{Novel Insights}

- Our case presented with plaque-like primary OC with a unique linear configuration of both lesions.

- The extensive scalp involvement in our case had caused significant disfigurement.

- The lesions in our case emerged during adulthood with progressive course invading adjacent skin in a gradual horizontal manner.

- Our patient developed OC primarily without any predisposing factor, associated feature, or metabolic disorder.

\section{Keywords}

Osteoma cutis · Skin - Calcification - Bone formation ·

Alopecia

\section{Abstract \\ Osteoma cutis (OC) or cutaneous ossification refers to un- common bone formation in the skin. Primary OC develops}

without any predisposing factor or pre-existing lesion, whereas secondary $\mathrm{OC}$ sets out as a dystrophic ossification following traumatic, cicatricial, and neoplastic factors or other cutaneous inflammations. Herein, we report a rare case of long-standing progressive primary $\mathrm{OC}$ of the scalp resected in 3 sessions with no recurrence after 1 year.

(c) 2021 S. Karger AG, Basel

$\begin{aligned} & \text { karger@karger.com } \\ & \text { www.karger.com/sad }\end{aligned}$
Karger ${ }^{\prime /}$

Mehdi Gheisari

Skin Research Center, Shohada-E Tajrish Educational Hospital Qods Sq.

Tehran 1989934148 (Iran)

mgheisari@sbmu.ac.ir 


\section{Introduction}

Osteoma cutis (OC) or cutaneous ossification refers to uncommon bone formation in the skin [1]. Primary OC develops without any predisposing factor or pre-existing lesion, whereas secondary OC sets out as a dystrophic ossification following traumatic, cicatricial, and neoplastic factors or other cutaneous inflammations [2].

Although primary OC behaves as a benign lesion, it may lead to noticeable deformity and psychosocial concerns for patients. Herein, we report a rare case of longstanding progressive primary OC of the scalp.

\section{Case Presentation}

A 55-year-old woman presented to our dermatology clinic complaining of the gradual growth of 2 hard plaques on her scalp. She denied any predisposing skin lesions, as well as pruritus, pain, or any other symptoms. The plaques of 20 -year duration were progressively enlarging with development of secondary alopecia. She was also anxious about the disfigurement caused by these lesions. She did not mention any history of surgical intervention, acne, trauma, or other dermatologic diseases. Her past medical history was negative for any diseases related to her present condition.

At the time of our consultation, we observed 2 giant nontender firm linear plaques, which were extended bilaterally from the frontal area to the occipital area. Both plaques had a yellow-brownish color and were covered with white papules. The right plaque was $5 \times 20 \mathrm{~cm}$, and the left one was about $10 \times 5 \mathrm{~cm}$ (Fig. 1). Scaling or erythema was not noted over or around the plaques. Also, no other similar skin lesions were observed elsewhere.
Microscopic examination of the skin specimen revealed bone formation in the dermis and subcutaneous tissue with stromal fat devoid of hematopoietic cells (Fig. 2). Laboratory data including thyroid function test, lipid profile, calcium, phosphorus, alkaline phosphatase, 25-hydroxy vitamin $\mathrm{D} 3$, parathyroid hormone, and 24-h urine analysis were all in the normal range. The head and neck MRI showed calcifications (osteomas) in the scalp skin without any involvement of deeper structures. Multistep resection of the plaques in 3 sessions was performed, and no recurrence was observed after 1 year.

\section{Discussion}

OC is characterized by an ectopic bone formation in the skin [3]. This condition mostly develops among females and in the second and third decades of life [2].

Primary ossification develops in the normal skin while the secondary type mainly emerges in the injured tissue [3]. The prevalence of secondary OC is higher than the primary type. Some inflammatory disorders such as morphea profounda [4], acne vulgaris, cutis laxa-like pseudoxanthoma elasticum [5], basal cell carcinoma [6, 7], and other neoplasia are among the causes of secondary OC.

There is no underlying cause for primary OC; however, it may be found in the context of some disorders including Albright's hereditary osteodystrophy, myositis ossificans progressiva, fibrodysplasia ossificans progressiva, and progressive osseous heteroplasia [8]. In these
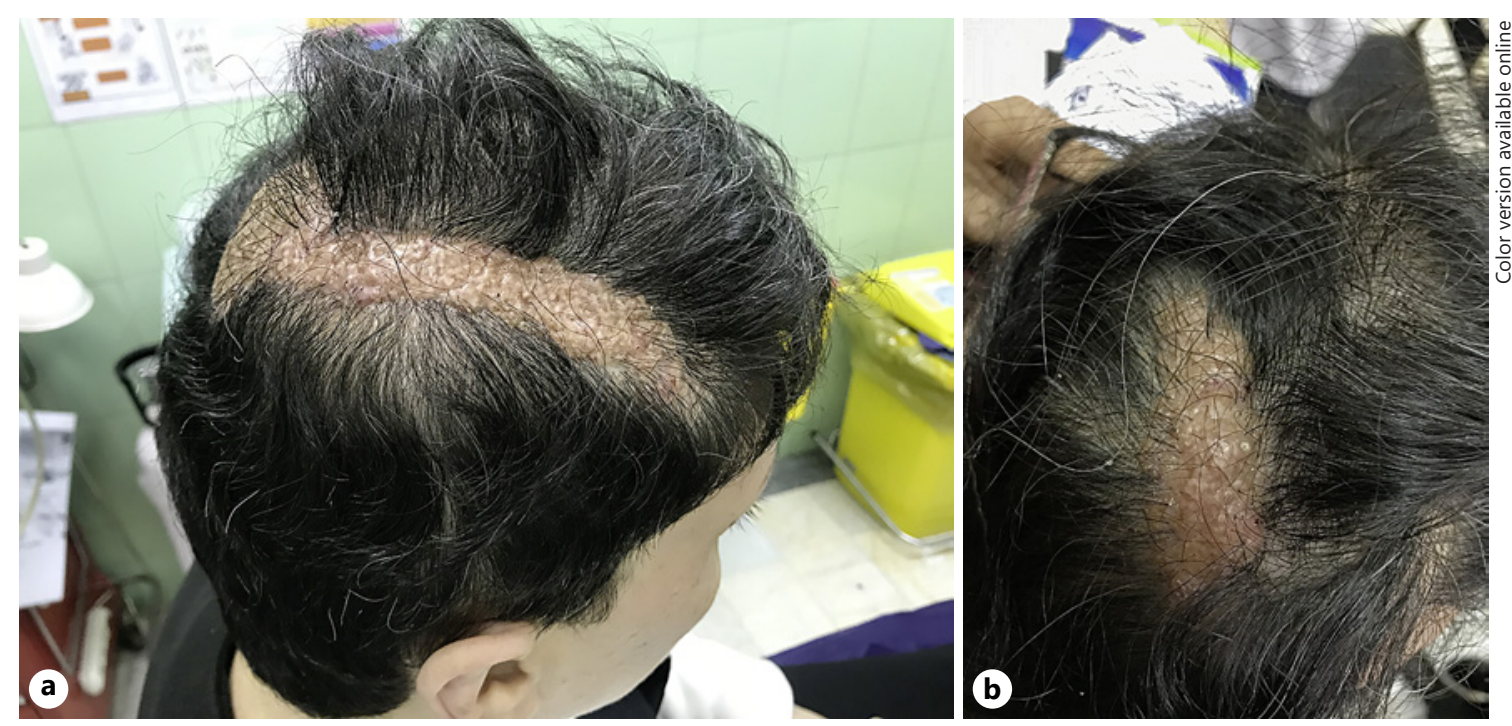

Fig. 1. Giant linear plaques extended bilaterally from the frontal area to the vertex area covered with white papules: right-side lesion (a) and left-side lesion (b). 



Fig. 2. Bone formation in the dermis and subcutaneous tissue with stromal fat devoid of hematopoietic cells. H\&E staining. $\times 40(\mathbf{a})$ and $\times 100(\mathbf{b})$.

syndromes, which mostly develop in the first years of life, a predisposing genetic factor and a distinctive phenotype also present sometimes with a metabolic disorder. OC can be the first clinical presentation of these disorders [9].

Primary OC etiology remains unknown, and the diagnosis is made based on the clinical features and radiological assessment. Microscopic examination representing mature bone tissue organizing in spicules or sheets of compact bone confirms the diagnosis. Also, distinguishable osteocytes and rarely Haversian system may be detected while Howship's lacunae and osteoclasts are extremely rare findings [10].

Primary OC lesions, either multiple or single, have been reported on the face, scalp, trunk, breast, extremities, and buttocks [11]. Based on their clinical manifestations, these lesions are classified into 4 groups: solitary, widespread, plaque-like, and miliary osteomas of the face [12].

Worret and Burgdorf reported the first case of OC in plaque in 1978 [13]. This term defines a congenital, idiopathic, and plaque-like primary OC [14]; however, it has been reported occasionally in older children or even adults $[1,15]$. The main complaints of these patients are the appearance, physical discomfort, and transepidermal elimination [13]. There are several novelties in our case. First of all, our patient presented with plaque-like primary OC with a unique linear configuration of both le- sions. Secondly, the extensive scalp involvement had caused significant disfigurement. Thirdly, the lesions had emerged during adulthood with progressive course invading adjacent skin in a gradual horizontal manner without any vertical invasion. Additionally, our patient developed OC primarily without any predisposing factor, associated feature, or metabolic disorder.

Management of OC mainly depends on the location and extension of the lesions. Excision and primary closure is the mainstay of the treatment for both primary and secondary $\mathrm{OC}$ to achieve quick recovery with the least chance of local recurrence and scarring [15]. Erbium:YAG laser, topical tretinoin, curettage, and dermabrasion are the alternatives for miliary osteomas [16].

\section{Conclusion}

This rare case shows that primary OC may develop with variable clinical features without distinct boundaries between different types.

\section{Acknowledgements}

None to declare. 


\section{Statement of Ethics}

All the study protocols have been approved by the Ethics Committee of the Shahid Beheshti University of Medical Sciences. Also, this research was conducted ethically in accordance with the World Medical Association Declaration of Helsinki. The patient has given written informed consent to publish photos and details of the case.

\section{Conflict of Interest Statement}

The authors declare that they have no conflicts of interest.

\section{Funding Sources}

None to declare.

\section{Author Contributions}

Each author has contributed sufficiently and met the criteria for authorship. Herein, we state all the authorships. Farnaz Araghi is the main author and contributed to data acquisition and manuscript preparation. Sahar Dadkhahfar and Mohammadreza Tabary contributed to data acquisition, manuscript writing, and editing. Azadeh Rakhshan contributed to performing laboratory tests and reporting (pathology). Mehdi Gheisari is the corresponding author and designed and supervised all the aspects and contributed to manuscript editing.

\section{References}

1 Haro R, Revelles JM, Angulo J, Fariña MC, Martín L, Requena L. Plaque-like osteoma cutis with transepidermal elimination. J Cutan Pathol. 2009;36(5):591-3.

2 Navarrete MR, Memije M-EV, Guzman RA, Solana AC, Lopez GER, Esmenjaud JR. Dermoscopic and histopathological findings in osteoma cutis involving the face and scalp. Dermatol Pract Concept. 2019;9(1): 24-7.

3 Davis MD, Pittelkow MR, Lindor NM, Lundstrom CE, Fitzpatrick LA. Progressive extensive osteoma cutis associated with dysmorphic features: a new syndrome? Case report and review of the literature. Br J Dermatol. 2002;146(6):1075-80.

4 Ahn SK, Won JH, Choi EH, Kim SC, Lee SH. Perforating plate-like osteoma cutis in a man with solitary morphoea profunda. Br J Dermatol. 1996;134(5):949-52.
5 Choi GS, Kang DS, Chung JJ, Lee MG. Osteoma cutis coexisting with cutis laxa-like pseudoxanthoma elasticum. J Am Acad Dermatol. 2000;43(2 Pt 2):337-9.

6 Shoji T, Burlage AM, Bhawan J. Basal cell carcinoma with massive ossification. Am J Dermatopathol. 1999;21(1):34-6.

7 Boyd AS, King LE Jr. Basal cell carcinoma with ossification. J Am Acad Dermatol. 1998; 38(6 Pt 1):906-10.

8 Kaplan FS, Shore EM. Progressive osseous heteroplasia. J Bone Miner Res. 2000;15(11): 2084-94.

9 Mast AM, Hansen R. Multiple papules on the elbows. Congenital osteoma cutis. Arch Dermatol. 1997;133(6):777, 780.

10 Bergonse FN, Nico MM, Kavamura MI, Sotto MN. Miliary osteoma of the face: a report of 4 cases and review of the literature. Cutis. 2002; 69(5):383-6.
11 Altman JF, Nehal KS, Busam KJ, Halpern AC Treatment of primary miliary osteoma cutis with incision, curettage, and primary closure. J Am Acad Dermatol. 2001;44(1):96-9.

12 Sethuraman G, Malhotra AK, Khaitan BK, Kumar R, Sharma VK, Kabra M, et al. Osteoma cutis in pseudohypoparathyroidism. Clin Exp Dermatol. 2006;31(2):225-7.

13 Orme CM, Hale CS, Meehan SA, Long W. Plate-like osteoma cutis. Dermatol Online J. 2015;20(12):13030

14 Hernandez-Martin A, Perez-Mies B, Torrelo A. Congenital plate-like osteoma cutis in an infant. Pediatr Dermatol. 2009;26(4):479-81.

15 Henrich DE, Morrison JA, Holmes DK. Primary osteoma cutis. Otolaryngol Head Neck Surg. 1997 Dec;117(6):S98-100.

16 Ayaviri NA, Nahas FX, Barbosa MV, Farah $\mathrm{AB}$, de Arimatéia Mendes J, Ferreira LM. Isolated primary osteoma cutis of the head: case report. Can J Plast Surg. 2006;14(1):33. 